\title{
Performance and time stability of Ir/SiC X-ray mirror coatings for ATHENA
}

\author{
Svendsen, S.; Massahi, S.; Ferreira, D. D. M.; Christensen, F. E.; Jafari, A.; Henriksen, P. L.; Collon, M.;
} Landgraf, B.; Girou, D.; Krumrey, M.

Total number of authors:

14

Published in:

Proceedings of SPIE 11119, Optics for EUV, X-Ray, and Gamma-Ray Astronomy IX

Link to article, DOI:

$10.1117 / 12.2528664$

Publication date:

2019

Document Version

Publisher's PDF, also known as Version of record

Link back to DTU Orbit

Citation $(A P A)$ :

Svendsen, S., Massahi, S., Ferreira, D. D. M., Christensen, F. E., Jafari, A., Henriksen, P. L., Collon, M., Landgraf, B., Girou, D., Krumrey, M., Cibik, L., Schubert, A., Handick, E., \& Shortt, B. (2019). Performance and time stability of Ir/SiC X-ray mirror coatings for ATHENA. In S. L. O'Dell, \& G. Pareschi (Eds.), Proceedings of SPIE 11119, Optics for EUV, X-Ray, and Gamma-Ray Astronomy IX (Vol. 11119, pp. 107 - 116). SPIE International Society for Optical Engineering. Proceedings of SPIE - The International Society for Optical Engineering https://doi.org/10.1117/12.2528664

\section{General rights}

Copyright and moral rights for the publications made accessible in the public portal are retained by the authors and/or other copyright owners and it is a condition of accessing publications that users recognise and abide by the legal requirements associated with these rights.

- Users may download and print one copy of any publication from the public portal for the purpose of private study or research.

- You may not further distribute the material or use it for any profit-making activity or commercial gain

- You may freely distribute the URL identifying the publication in the public portal 


\section{Performance and time stability of $\mathrm{Ir} /$ SiC X-ray mirror coatings for ATHENA}

S. Svendsen, S. Massahi, D. D. M. Ferreira, F. E. Christensen, A. Jafari, et al.

S. Svendsen, S. Massahi, D. D. M. Ferreira, F. E. Christensen, A. Jafari, P. L. Henriksen, M. Collon, B. Landgraf, D. Girou, M. Krumrey, L. Cibik, A. Schubert, E. Handick, B. Shortt, "Performance and time stability of Ir/SiC Xray mirror coatings for ATHENA," Proc. SPIE 11119, Optics for EUV, X-Ray, and Gamma-Ray Astronomy IX, 111190G (9 September 2019); doi: $10.1117 / 12.2528664$

Event: SPIE Optical Engineering + Applications, 2019, San Diego, California, United States 


\title{
Performance and time stability of $\mathrm{Ir} / \mathrm{SiC} \mathrm{X}$-ray mirror coatings for ATHENA
}

\author{
S. Svendsen ${ }^{a}$, S. Massahi ${ }^{a}$, D. D. M. Ferreira ${ }^{a}$, F. E. Christensen ${ }^{a}$, A. Jafari ${ }^{a}$, P. L. Henriksen ${ }^{a}$

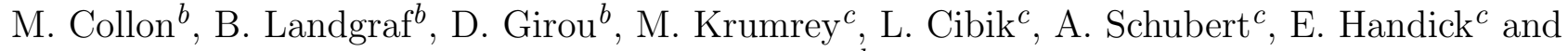 \\ B. Shortt ${ }^{d}$

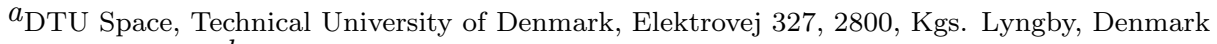

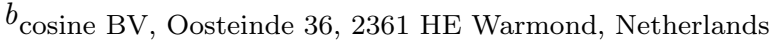 \\ ${ }^{c}$ Physikalisch-Technische Bundesanstalt (PTB), Abbestraße 2-12, 10587 Berlin, Germany

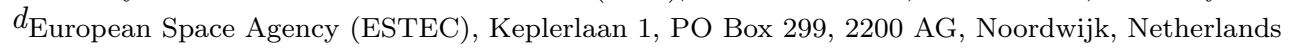

\begin{abstract}
Excellent X-ray reflective mirror coatings are key in order to meet the performance requirements of the ATHENA telescope. The baseline coating design of ATHENA was initially formed by $\operatorname{Ir} / \mathrm{B}_{4} \mathrm{C}$ but extensive studies have identified critical issues with the stability of the $\mathrm{B}_{4} \mathrm{C}$ top layer which shows strong evolution over time and appears incompatible with the industrialization processes required for the production of mirror modules.

Motivated by the need for a compatible top layer material to improve the telescope performance at low energies and based on simulated performance, a $\mathrm{SiC}$ top layer has been selected as the best substitute to $\mathrm{B}_{4} \mathrm{C}$. We report the latest development of $\mathrm{Ir} / \mathrm{SiC}$ bilayer coatings optimized for ATHENA and the characterization of coating performance and stability.
\end{abstract}

Keywords: ATHENA, X-ray mirrors, Silicon Pore Optics, X-ray optics, Ir/SiC, SiC, coating stability, thin film characterization

\section{INTRODUCTION}

The Advanced Telescope for High ENergy Astrophysics (ATHENA) is the next large X-ray observatory of the European Space Agency, scheduled to be launched in the early 2030s ${ }^{1}$. The X-ray optics of ATHENA are based on Silicon Pore Optics (SPO) coated with X-ray reflective thin films to enhance the reflectivity in the 0.3-12 $\mathrm{keV}$ operational range of the telescope. The thin film mirror coatings are developed and characterized at DTU Space $^{2-10}$.

While a single high- $\mathrm{Z}$ metallic coating provides good reflectivity across the energy range, the addition of a low-Z top layer material is critical to improve the low-energy performance of the telescope and reach the effective area requirements for the science objectives ${ }^{11}$. Based on simulated performance of the optimized mirror coating designs, Ir $/ \mathrm{B}_{4} \mathrm{C}$ bilayer coatings fulfill the effective area requirement at $1 \mathrm{keV}^{5,8}$. However, extensive studies on the stability and performance of $\mathrm{B}_{4} \mathrm{C}$ thin films produced at DTU Space have revealed several issues with the $\mathrm{B}_{4} \mathrm{C}$ top layer evolving over time and showing incompatibility with the industrialization processes for mirror production $^{8-10}$.

As a result, the $\mathrm{B}_{4} \mathrm{C}$ top layer was recently replaced by $\mathrm{SiC}$ for the mirror coating baseline design ${ }^{9,12}$. This new design assumes an optimized $\mathrm{Ir} / \mathrm{SiC}$ bilayer across all optic rings of $10 \mathrm{~nm}$ Ir with a $4 \mathrm{~nm}$ top layer of SiC. The simulated performance in Figure 1 shows the improvement in reflectivity $1 \mathrm{keV}$ by adding the SiC overcoat when compared to an Ir-only mirror coating.

The development and qualification in terms of stability, performance and stress of the $\mathrm{Ir} / \mathrm{SiC}$ mirror coatings is currently ongoing at DTU Space. These studies also involve environmental testing such as compatibility with the chemical, thermal and mechanical processes needed for stacking of SPO plates into mirror modules.

A crucial part of assessing $\mathrm{SiC}$ as a succesful candidate coating material for future space missions involves

Further author information - send correspondence to:

Sara Svendsen, e-mail: sasv@space.dtu.dk

Optics for EUV, X-Ray, and Gamma-Ray Astronomy IX, edited by Stephen L. O'Dell, Giovanni Pareschi, Proc. of SPIE Vol. 11119, 111190G · @ 2019 SPIE · CCC code: 0277-786X/19/\$21 · doi: 10.1117/12.2528664 


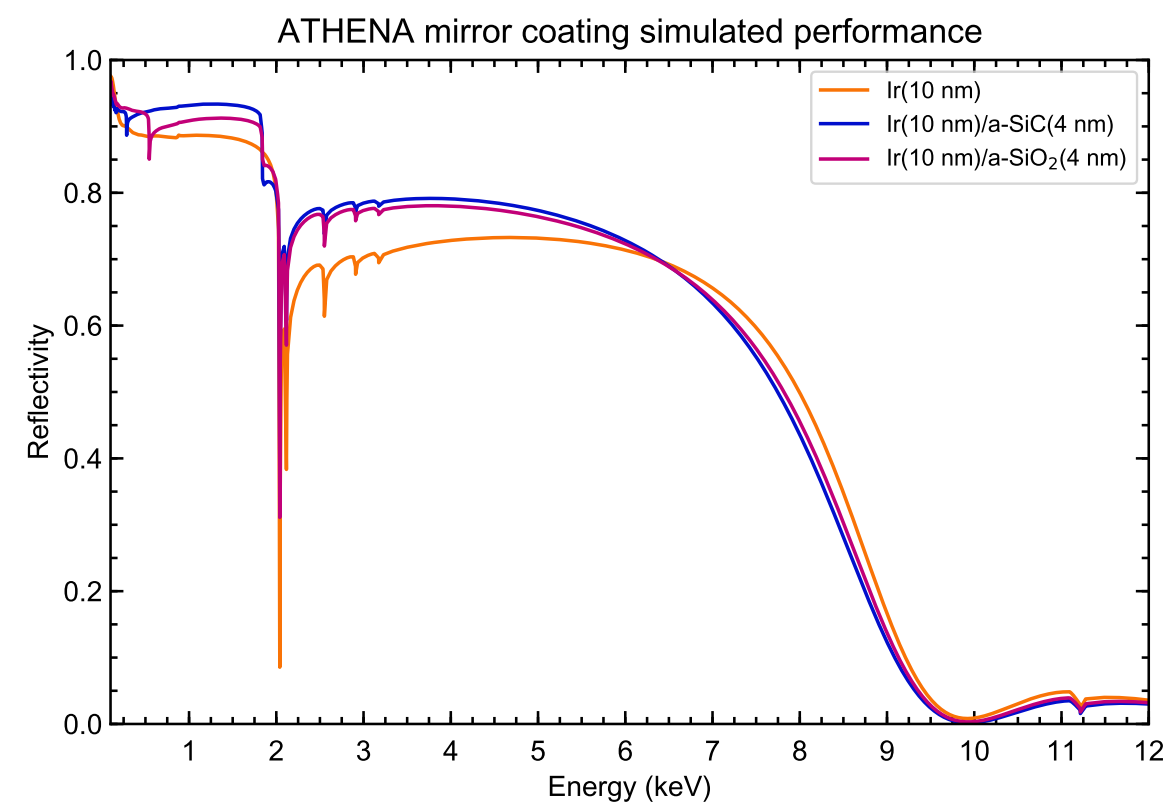

Figure 1: Simulated 0.1-12 keV performance of $\mathrm{Ir}, \mathrm{Ir} / \mathrm{SiC}$ and $\mathrm{Ir} / \mathrm{SiO}_{2}$ coatings at a fixed grazing incidence angle of $0.6 \mathrm{deg}$. Average RMS roughnesses of $0.45 \mathrm{~nm}$ are assumed in each case.

investigating the short-term stability of $\mathrm{SiC}$ thin films produced in the coating facility that will be used for the flight production of ATHENA mirrors ${ }^{13}$. The surface of $\mathrm{SiC}$ thin films is expected to oxidize when exposed to the atmosphere which likely forms a protective cap layer preventing further evolution throughout the film ${ }^{14}$. However, the rate at which this oxide layer forms as well as the impact on the overall coating composition has to be established.

Figure 1 also compares the optimized bilayer coating to the most severe case in which the entire SiC layer has been oxidized and degraded from a nominal density of a-SiC to a-SiO${ }_{2}\left(3.112 \mathrm{~g} / \mathrm{cm}^{3}\right.$ and $2.19 \mathrm{~g} / \mathrm{cm}^{3}$, respectively*). This would affect the overall coating performance below $7 \mathrm{keV}$. In addition, as will be the case for all of the low-Z candidate coatings $\left(\mathrm{SiC}, \mathrm{B}_{4} \mathrm{C}, \mathrm{C}\right)$, the incorporation of oxygen in the coating surface will introduce an unwanted O K absorption edge.

Preliminary tests on the long-term stability of SiC single-layers coated at DTU Space motivated a systematic study on the time stability and performance of $\mathrm{SiC}$ films coated in the recently installed coating chamber located at cosine BV, the Netherlands which has been purchased for the flight mirror production ${ }^{13}$. Similar stability studies were carried out on $\mathrm{B}_{4} \mathrm{C}$ films ${ }^{10}$. The focus of this paper is both long-term studies of $\mathrm{Ir} / \mathrm{SiC}$ bilayers and periodic multilayers as well as systematic studies on short-term stability and composition of SiC thin films.

\section{EXPERIMENTAL}

All thin film coatings considered in this study were produced using DC magnetron sputtering and include SiC single-layers as well as bilayers and periodic multilayers of $\mathrm{Ir} / \mathrm{SiC}$. The coatings were deposited onto double side polished $\mathrm{Si}(100)$ wafer substrates that were diced into $70 \times 10 \mathrm{~mm}^{2}$ pieces.

The thin film deposition was carried out in the coating facilities at DTU Space and at cosine BV. The process parameters for the different setups are similar, using a base pressure of $<10^{-6}$ mbar prior to coating to reduce contamination from the atmosphere. Ar was used as sputtering gas at pressures of $3.4-4.0 \cdot 10^{-3}$ mbar, depending on the coating chamber. A 300 second presputtering was performed before coating of each material. A honeycomb collimation mesh was installed in the path between the target and the sample carriers to reduce coating roughness ${ }^{16}$.

*Reflectivity based on the optical constants computed from the CXRO and LLNL atomic scattering factors in the IMD software $^{15}$ 


\subsection{Thin film characterization}

The presented X-ray reflectometry (XRR) data includes measurements from two different facilities. The $\theta-2 \theta$ scans at a fixed beam energy of $8.047 \mathrm{keV}(\mathrm{Cu} \mathrm{K} \alpha)$ were carried out using a Rigaku SmartLab X-ray Diffractometer operating with a parallel beam and a Ge(220)x2 monochromator.

The energy scans at 0.6 deg grazing incidence angle were measured at the PTB BESSY II Four Crystal Monochromator (FCM) beamline ${ }^{17}$.

XRR measurements were analysed with the IMD software ${ }^{15}$. The data was assigned statistical weights and fitted logarithmically using the Björck differential evolution algorithm using random sampling from the base parent population ${ }^{18}$.

X-ray photoelectron spectroscopy (XPS) was used to quantify the elemental composition of a SiC single-layer sample. The XPS measurements were carried out in a ThermoScientific K-Alpha using a monochromated Al $\mathrm{K} \alpha$ X-ray source with a spot size of $400 \mu \mathrm{m}^{2}$. An electron flood gun was used to avoid charge build-up on non-conductive materials.

The probing depth of the setup was 3-4 nm depending on the electron mean free path in the material. In order to characterize both the chemical composition and the structure of the $\mathrm{SiC}$ film, depth profiling was employed using an Ar ion beam at $3 \mathrm{keV}$ with a 20 second etch cycle. Survey scans and high resolution elemental scans were captured at each iteration.

\section{RESULTS}

The Ir/SiC long-term stability samples were characterized using $8.047 \mathrm{keV}$ XRR and energy scans through synchrotron radiation. Energy scans of bilayers are necessary to reveal possible changes in thickness and density of the low-Z top layer material since the high reflectance of the high-Z layer attenuates most signal from the low- $\mathrm{Z}$ overcoat and these parameters cannot be constrained from fits to $8.047 \mathrm{keV}$ angle scans.

The systematic short-term stability study involves four $\mathrm{SiC}$ single-layer thin films coated in the ATHENA coating facility. The coatings were designed with aimed thicknesses of $5 \mathrm{~nm}, 10 \mathrm{~nm}, 20 \mathrm{~nm}$ and $30 \mathrm{~nm}$, of which the latter was dedicated to XPS measurements. All samples were brought to DTU Space immediately after coating for characterization using XRR at $8.047 \mathrm{keV}$ and XPS at DTU Nanolab. In between measurements, the samples were stored at ambient conditions.

\subsection{Long term stability of $\mathrm{Ir} / \mathrm{SiC}$ coatings}

Figure 2 shows energy scans of an Ir/SiC bilayer sample coated at DTU Space. No significant discrepancy in reflectance is observed, indicating that the $\mathrm{SiC}$ top layer is stable from 3 months up to at least 18 months after coating.

Table 1: Fitted structure parameters from BESSY energy scan measurements at 0.6 deg grazing incidence of the $\mathrm{Ir} / \mathrm{SiC}$ bilayer coating (si6793). Fit parameter values marked with an asterisk were fixed to the listed value.

\begin{tabular}{l|lll|lll|lll}
\multicolumn{3}{c}{} & \multicolumn{3}{c}{ 3 months } & \multicolumn{3}{c}{$\mathbf{1 1}$ months } & \multicolumn{3}{c}{18 months } \\
\hline \hline & $\mathrm{z}(\mathrm{nm})$ & $\rho\left(\mathrm{g} / \mathrm{cm}^{3}\right)$ & $\sigma(\mathrm{nm})$ & $\mathrm{z}(\mathrm{nm})$ & $\rho\left(\mathrm{g} / \mathrm{cm}^{3}\right)$ & $\sigma(\mathrm{nm})$ & $\mathrm{z}(\mathrm{nm})$ & $\rho\left(\mathrm{g} / \mathrm{cm}^{3}\right)$ & $\sigma(\mathrm{nm})$ \\
\hline$(1) \mathrm{SiC}$ & 5.56 & 3.03 & 0.37 & 5.58 & 2.94 & 0.57 & 5.55 & 2.93 & 0.67 \\
$(2) \mathrm{Ir}$ & $9.70^{*}$ & - & $\sigma_{(1)}$ & $9.70^{*}$ & - & $\sigma_{(1)}$ & $9.70^{*}$ & - & $\sigma_{(1)}$ \\
$(3) \mathrm{a}-\mathrm{SiO}_{2}$ & $1.00^{*}$ & - & 0.72 & $1.00^{*}$ & - & 0.67 & $1.00^{*}$ & - & 0.77 \\
$(4) \mathrm{Si}$ (substrate) & - & $\sigma_{(3)}$ & - & $\sigma_{(3)}$ & - & $\sigma_{(3)}$ & & & \\
\hline \hline
\end{tabular}

The data was fitted using a simple model consisting of Ir with an SiC top layer. The best fit parameters given in Table 1 do not indicate any increase in $\mathrm{SiC}$ thickness. Instead, a slight decrease in density is observed. A limitation of energy scans is that the roughnesses are not well-constrained from the fit. Therefore, the surface and bilayer interface roughnesses were coupled. In order to measure potential evolution of the surface roughness, measurements at a low-energy XRR facility such the recently installed LEXR (Low-Energy X-ray Reflectometer) at DTU Space are necessary ${ }^{19}$.

The $\mathrm{Ir} / \mathrm{SiC}$ periodic multilayer sample was measured with $8.047 \mathrm{keV}$ XRR and the data was modelled as 9 


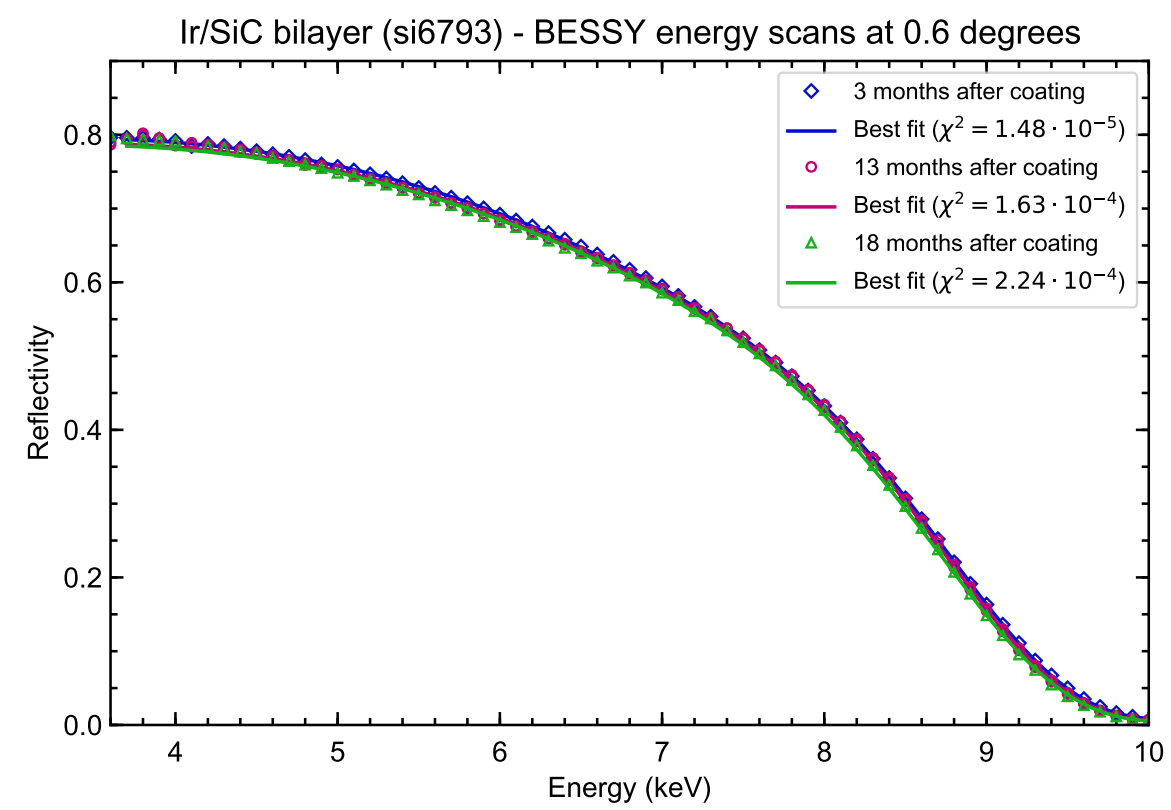

Figure 2: $\mathrm{Ir} / \mathrm{SiC}$ bilayer coatings measured at BESSY II at 0.6 deg incidence angle.

periodic bilayers with an independent $\mathrm{Ir} / \mathrm{SiC}$ cap layer. The measurements and best fits are presented in Figure 3 and Table 2. No evolution is observed at $8.047 \mathrm{keV}$ which indicates that the $\mathrm{SiC}$ cap layer has stabilized. The layer thickness of the $\mathrm{SiC}$ cap can be constrained within approximately $\pm 1 \mathrm{~nm}$.

The overlap of the measured reflectivity curves also indicates that no layer diffusion occurs between the measurements. It was previously shown through simulation that linear graded multilayers of the former $\mathrm{Ir} / \mathrm{B}_{4} \mathrm{C}$ baseline coating for the outer rings of the ATHENA optic could be optimized to improve the telescope effective area at 6 $\mathrm{keV}^{8}$. The stability of the $\mathrm{Ir} / \mathrm{SiC}$ multilayers demonstrates that producing similar multilayer coatings is feasible.

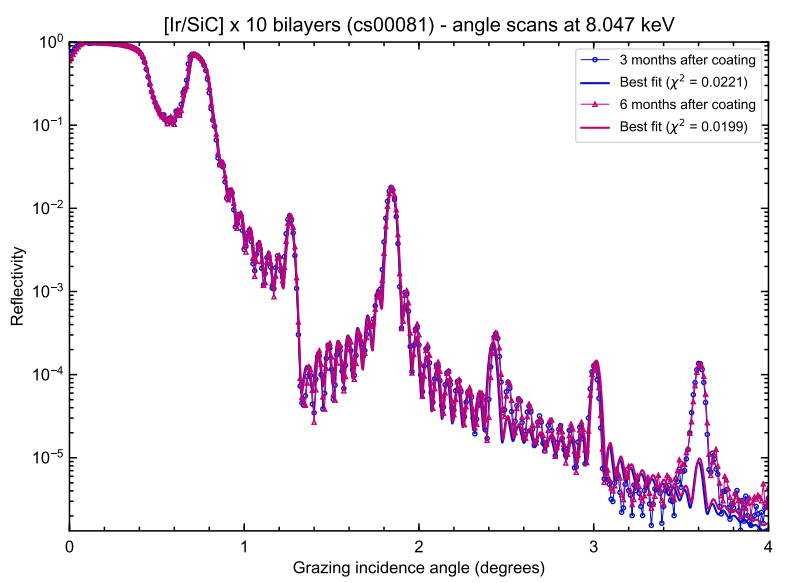

Figure 3: XRR at $8.047 \mathrm{keV}$ of the periodic multilayer coating.

\begin{tabular}{l|c|c} 
& 3 months & 6 months \\
\hline \hline$\Gamma_{\text {cap }}$ & 0.31 & 0.30 \\
$d_{\text {cap }}(\mathrm{nm})$ & 11.93 & 11.96 \\
$\rho_{\mathrm{SiC}, \text { cap }}\left(\mathrm{g} / \mathrm{cm}^{3}\right)$ & 3.07 & 3.02 \\
$\sigma_{\mathrm{SiC}, \text { cap }}(\mathrm{nm})$ & 0.82 & 0.86 \\
$\Gamma$ & 0.50 & 0.50 \\
$d(\mathrm{~nm})$ & 7.42 & 7.41 \\
$\sigma_{\mathrm{SiC} / \mathrm{Ir}}(\mathrm{nm})$ & 0.61 & 0.61 \\
$\sigma_{\mathrm{Ir} / \mathrm{SiC}}(\mathrm{nm})$ & 0.50 & 0.50 \\
$\sigma_{\mathrm{a}-\mathrm{SiO}}(\mathrm{nm})$ & 0.27 & 0.26 \\
\hline \hline
\end{tabular}

Table 2: Fitted multilayer structure parameters from 8.047 XRR measurements of the 10 periodic bilayers of $\mathrm{Ir} / \mathrm{SiC}$. 


\subsection{Short-term stability of $\mathrm{SiC}$ single-layer coatings}

The $\mathrm{Ir} / \mathrm{SiC}$ coated samples for long-term stability testing show no temporal evolution from the earliest reference measurements at 3 months after coating and onwards. This suggests that the SiC oxidizes immediately after exposure to the atmosphere and that this evolution ceases within the first 3 months. It is likely that the formation of the $\mathrm{SiO}_{2}$ overcoat creates a protective layer that prevents further oxidation throughout the $\mathrm{SiC}$ coating. ${ }^{14}$ This has motivated a systematic short-term stability study to gain a thorough understanding of the chemical states and structure of the $\mathrm{SiC}$ thin films, as well as mapping the rate of evolution over the course of realistic time scales for the production of the ATHENA mirror in terms of storage and handling before stacking and mirror module fabrication.

\subsubsection{XPS depth profile analysis of SiC single-layer coatings}

XPS depth-profiling measurements of the $\sim 30 \mathrm{~nm}$ thick $\mathrm{SiC}$ single-layers were carried out 1 week, 2 weeks and 1 month after coating. The peak components were deconvolved using Gaussian-Lorentzian line shapes using the CasaXPS software ${ }^{20}$. The XPS background was modelled with a Shirley profile.

It should be noted in the following that the use of XPS depth-profiling imposes a limitation on the interpretation of spectra since it cannot be excluded that the ion beam etching impacts the XPS measurements by modifying or destroying the material bond structures.

The main photoelectron core level and Auger lines of elements present throughout the film were identified from the survey spectra ${ }^{21}$. High resolution spectra of Si 2p, C 1s, O 1s, N 1s and Fe 2p were acquired in each etch cycle. As seen in Figure 4, the XPS depth profiling reveals a distinct layer structure composed of a surface layer, a main film structure and the transition layer between the substrate native oxide and the initial $\mathrm{SiC}$ growth layer. For the $\mathrm{SiC}$ coatings measured 2 weeks and 1 month after coating, the $\mathrm{O} 1$ s peak appears further into the film surface. Unlike the 1 week measurement where the Si $2 p$ are only shifted at the very surface, the latter measurements also reveal a chemical shift of Si $2 p$ after a few etch cycles. This offset could either be an effect of interface induced band bending, or it could indicate growth of the surface layer or gradual oxidation into the surface.

Table 3: Binding energies of the detected spectral features of the $30 \mathrm{~nm} \mathrm{SiC} \mathrm{coating} \mathrm{and} \mathrm{the} \mathrm{proposed} \mathrm{peak}$ identification from the XPS depth profile analysis.

\begin{tabular}{|c|c|c|c|c|c|c|c|c|}
\hline & \multicolumn{2}{|c|}{ Si 2p } & \multicolumn{2}{|r|}{ C 1s } & \multicolumn{2}{|r|}{$01 \mathrm{~s}$} & \multicolumn{2}{|c|}{ Other } \\
\hline (1) Surface & $\begin{array}{l}99.6-100.3 \mathrm{eV} \\
100.2-100.9 \mathrm{eV} \\
101.0-101.6 \mathrm{eV} \\
102.2 \mathrm{eV}\end{array}$ & $\begin{array}{l}\mathrm{Si}-\mathrm{C} \text { or } \mathrm{Si}-\mathrm{Si}\left(2 \mathrm{p}_{3 / 2}\right) \\
\mathrm{Si}-\mathrm{C} \text { or } \mathrm{Si}-\mathrm{Si}\left(2 \mathrm{p}_{1 / 2}\right) \\
\mathrm{Si}-\mathrm{C} \text { or } \mathrm{Si}-\mathrm{N} \\
\mathrm{Si}-\mathrm{O}\end{array}$ & $\begin{array}{l}282.7-282.9 \mathrm{eV} \\
283.5-284.0 \mathrm{eV} \\
287.0-287.4 \mathrm{eV}\end{array}$ & $\begin{array}{l}\mathrm{Si}-\mathrm{C}, \mathrm{C}-\mathrm{C} \text { or } \mathrm{C}-\mathrm{H} \\
\mathrm{Si}-\mathrm{C}, \mathrm{C}-\mathrm{C}, \mathrm{C}-\mathrm{OH} \text { or } \mathrm{C}-\mathrm{O}-\mathrm{C} \\
\mathrm{C}-\mathrm{O} \text { or } \mathrm{C}=\mathrm{O}\end{array}$ & $\begin{array}{l}531.5 \mathrm{eV} \\
532.0 \mathrm{eV} \\
533.6 \mathrm{eV} \\
534.0 \mathrm{eV}\end{array}$ & $\begin{array}{l}\mathrm{Si}-\mathrm{O}, \mathrm{C}-\mathrm{O} \text { or } \mathrm{C}=\mathrm{O} \\
\mathrm{Si}-\mathrm{O} \text { or } \mathrm{C}=\mathrm{O} \\
\mathrm{C}-\mathrm{OH} \text { or } \mathrm{C}-\mathrm{O}-\mathrm{C} \\
\mathrm{C}-\mathrm{OH} \text { or } \mathrm{C}-\mathrm{O}-\mathrm{C}\end{array}$ & $\begin{array}{l}397.5 \mathrm{eV} \\
399.0 \mathrm{eV}\end{array}$ & $\begin{array}{l}\mathbf{N} 1 \mathbf{s} \\
\mathrm{Si}_{3} \mathrm{~N}_{4} \\
\mathrm{NH}_{3}, \mathrm{C}_{5} \mathrm{H}_{5} \mathrm{~N}\end{array}$ \\
\hline (2) Film & $\begin{array}{l}99.5-99.9 \mathrm{eV} \\
100.1-100.6 \mathrm{eV} \\
101.0-101.9 \mathrm{eV} \\
\end{array}$ & $\begin{array}{l}\mathrm{Si}-\mathrm{C} \text { or } \mathrm{Si}-\mathrm{Si}\left(2 \mathrm{p}_{3 / 2}\right) \\
\mathrm{Si}-\mathrm{C} \text { or } \mathrm{Si}-\mathrm{Si}\left(2 \mathrm{p}_{1 / 2}\right) \\
\mathrm{Si}-\mathrm{C}\end{array}$ & $\begin{array}{l}282.6-282.9 \mathrm{eV} \\
283.1-283.8 \mathrm{eV}\end{array}$ & $\begin{array}{l}\text { Si-C } \\
\text { Si-C }\end{array}$ & & & $\begin{array}{l}707.0 \mathrm{eV} \\
720.0 \mathrm{eV}\end{array}$ & $\begin{array}{l}\text { Fe } 2 \mathbf{p} \\
\text { Fe } 2 p_{3 / 2} \\
\text { Fe } 2 p_{1 / 2}\end{array}$ \\
\hline (3) Interface & $\begin{array}{l}99.0-99.9 \mathrm{eV} \\
100.2-101.1 \mathrm{eV} \\
102.1\end{array}$ & $\begin{array}{l}\mathrm{Si}-\mathrm{Si}\left(2 \mathrm{p}_{3 / 2}\right) \\
\mathrm{Si}-\mathrm{C} \text { or } \mathrm{Si}-\mathrm{Si}\left(2 \mathrm{p}_{1 / 2}\right) \\
\mathrm{Si}-\mathrm{O}\end{array}$ & $\begin{array}{l}282.6-282.9 \mathrm{eV} \\
283.1-283.8 \mathrm{eV} \\
284.0-284.5 \mathrm{eV}\end{array}$ & $\begin{array}{l}\mathrm{Si}-\mathrm{C} \\
\mathrm{Si}-\mathrm{C} \text { or } \mathrm{C}-\mathrm{C} \\
\mathrm{C}-\mathrm{C}\end{array}$ & $\begin{array}{l}531.5 \mathrm{eV} \\
532.0 \mathrm{eV}\end{array}$ & $\begin{array}{l}\mathrm{O}-\mathrm{Si} \\
\mathrm{O}-\mathrm{Si}\end{array}$ & & \\
\hline (4) Substrate & $99.0-99.5 \mathrm{eV}$ & $\mathrm{Si}-\mathrm{Si}$ & & & & & & \\
\hline
\end{tabular}

Throughout the main part of the $\mathrm{SiC}$ films, Si 2p peaks at $100.0 \mathrm{eV}, 100.4-100.5 \mathrm{eV}$ and $101.3-101.9 \mathrm{eV}$ are observed. Correspondingly, $\mathrm{C}$ 1s peaks are found at 282.6-282.9 eV and 283.1-283.8 eV. These are attributed to $\mathrm{Si}-\mathrm{C}$ bonds ${ }^{2-24}$. Si and $\mathrm{C}$ are found in roughly equal ratios, suggesting that the film is close to stoichiometric SiC. A small concentration of Fe is detected throughout the film at the Fe 2p peaks at $707.0 \mathrm{eV}$ and $720.0 \mathrm{eV}$. This is likely a result of either contamination from the structure surrounding the magnetron, or from target impurities as the thin film coatings were produced from $99.5 \%$ purity $\mathrm{SiC}$ with the main contaminants being $\mathrm{Fe}$ and $\mathrm{Al}$. The Fe peak is not observed in the surface or the film-to-substrate transition layer which is likely due to attenuation from increased background levels in the spectrum region.

The surface region reveals a change in composition. Si 2p is found between 99.7-100.9 eV, again indicative of $\mathrm{Si}-\mathrm{Si}$ (associated with the $2 \mathrm{p}_{1 / 2}, 2 \mathrm{p}_{3 / 2}$ splitting of the Si doublet) or Si-C, and at 101.1-101.6 eV which could be 

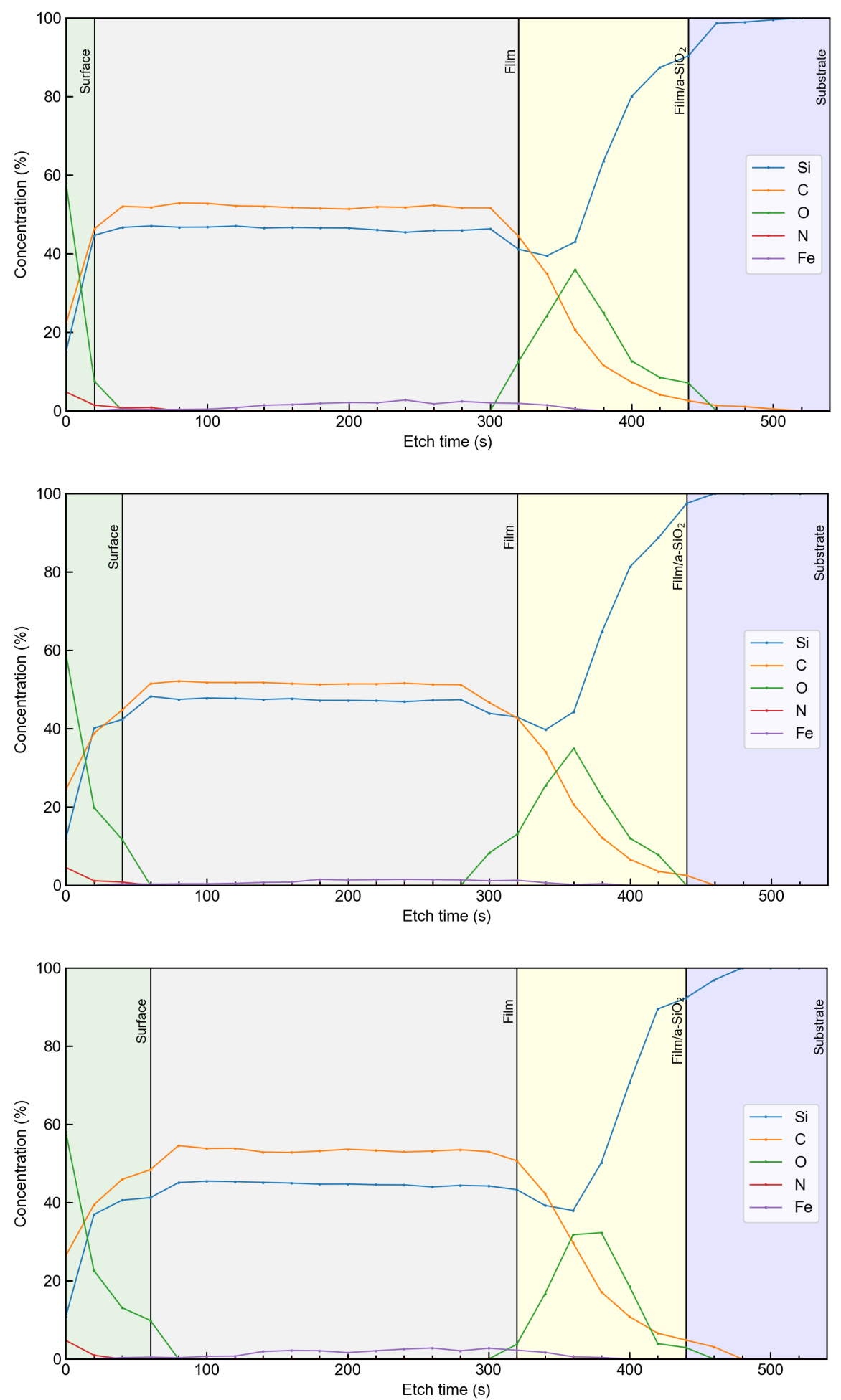

Figure 4: XPS depth profiling measured 1 week (top), 2 weeks (middle) and 1 month (bottom) after coating showing the main elemental concentrations as a function of etching time. 
either $\mathrm{Si}-\mathrm{O}$ or $\mathrm{Si}-\mathrm{N}$ bonds ${ }^{25,26}$. The presence of $\mathrm{Si}-\mathrm{C}$ bonds is supported by $\mathrm{C}$ 1s peaks observed at 282.7-282.9 $\mathrm{eV}$ and $283.5-283.7 \mathrm{eV}$. O 1s peaks are found around 531.0-531.7 eV and 532.0 eV consistent with Si-O and C-O bonds. It is observed that the chemical shifts that distinguish the film from the surface region, as well as the $\mathrm{O}$ $1 \mathrm{~s}$ peaks, reach further into the top layers as time progresses. The surface also contains composite $\mathrm{O}$ 1s features at 530.0 eV and 531.1-531.7 eV but additional peaks appear around 533.6 eV and $534.0 \mathrm{eV}$ after 2 weeks and 1 month, respectively. This is likely a chemical shift of the C-OH/C-O-C lines attributed to hydrocarbons.

The top of the film surface (etch time $=0 \mathrm{~s}$ ) shows $\mathrm{N}$ 1s peaks at $397.1-397.7 \mathrm{eV}$ and $399.0 \mathrm{eV}$ that indicate $\mathrm{N}$ incorporation, perhaps associated with silicon oxynitrides $\left(\mathrm{SiO}_{x} \mathrm{~N}_{y}\right)^{27}$. The $101.0 \mathrm{eV}$ Si 2p peak could be attributed to a $\mathrm{Si}-\mathrm{N}$ bond. Si 2p features furthermore appear at 99.9-100.2 eV and 102.2-102.4 eV, indicating the presence of $\mathrm{Si}-\mathrm{C}$, and $\mathrm{Si}-\mathrm{O}$ associated with $\mathrm{SiO}_{2}$. Several shifted photoemission peaks via $\mathrm{C}$ 1s are measured in the surface at $282.8 \mathrm{eV}, 284.0 \mathrm{eV}$ and $287.0-287.4 \mathrm{eV}$. These can be ascribed to states of hydrocarbon bonds (adventitious carbon) which contaminate the surface ${ }^{26}$. The $287.3 \mathrm{eV}$ peak could however also represent an oxide state of coated $\mathrm{C}$ while the $282.8 \mathrm{eV}$ line is likely a Si-C feature. The peaks around $532.0 \mathrm{eV}$ observed in both the surface and the native oxide layer are consistent with either $\mathrm{Si}-\mathrm{O}$ bonds of $\mathrm{SiO}_{2}$ or $\mathrm{C}=\mathrm{O}^{24,28}$.

\subsubsection{XRR measurements at $8.047 \mathrm{keV}$}

Figure 5 shows $8.047 \mathrm{XRR}$ measurements of the four $\mathrm{SiC}$ single-layer coatings measured systematically after coating. The gradual shift of the Kiessig fringes indicates that the films grow in thickness over time. The decrease in amplitude of the fringes can be ascribed to a gradual increase in surface roughness.

Table 4: Model parameters for the SiC single-layer coatings measured systematically with XRR after deposition. Fit parameter values marked with an asterisk were fixed to the listed value.

\begin{tabular}{|c|c|c|c|c|c|c|c|c|c|}
\hline & \multicolumn{3}{|c|}{$\operatorname{cs} 00090(\sim 5 \mathrm{~nm})$} & \multicolumn{3}{|c|}{$\operatorname{cs00091}(\sim 10 \mathrm{~nm})$} & \multicolumn{3}{|c|}{$\operatorname{cs00092}(\sim 20 \mathrm{~nm})$} \\
\hline 1 day & $\mathrm{z}(\mathrm{nm})$ & $\rho\left(\mathrm{g} / \mathrm{cm}^{3}\right)$ & $\sigma(\mathrm{nm})$ & $\mathrm{z}(\mathrm{nm})$ & $\rho\left(\mathrm{g} / \mathrm{cm}^{3}\right)$ & $\sigma(\mathrm{nm})$ & $\mathrm{z}(\mathrm{nm})$ & $\rho\left(\mathrm{g} / \mathrm{cm}^{3}\right)$ & $\sigma(\mathrm{nm})$ \\
\hline (1) $\mathrm{SiO}_{2}$ & 3.87 & 2.75 & 0.60 & 1.32 & 2.29 & 0.27 & 1.53 & 2.36 & 0.36 \\
\hline (2) $\mathrm{SiC}$ & 1.39 & 1.79 & $\sigma_{(1)}$ & 8.06 & 2.80 & $\sigma_{(1)}$ & 16.85 & 2.99 & $\sigma_{(1)}$ \\
\hline (3) $\mathrm{SiC}$ & - & - & - & 1.15 & 2.09 & $\sigma_{(1)}$ & 0.78 & 1.92 & $\sigma_{(1)}$ \\
\hline (4) $a-\mathrm{SiO}_{2}$ & $1.00^{*}$ & - & 0.55 & $1.00^{*}$ & - & 0.29 & $1.00^{*}$ & - & 0.50 \\
\hline (5) $\mathrm{Si}$ (sub.) & - & - & $\sigma_{(4)}$ & - & - & $\sigma_{(4)}$ & - & - & $\sigma_{(4)}$ \\
\hline 1 week & $\mathrm{z}(\mathrm{nm})$ & $\rho\left(\mathrm{g} / \mathrm{cm}^{3}\right)$ & $\sigma(\mathrm{nm})$ & $\mathrm{z}(\mathrm{nm})$ & $\rho\left(\mathrm{g} / \mathrm{cm}^{3}\right)$ & $\sigma(\mathrm{nm})$ & $\mathrm{z}(\mathrm{nm})$ & $\rho\left(\mathrm{g} / \mathrm{cm}^{3}\right)$ & $\sigma(\mathrm{nm})$ \\
\hline (1) $\mathrm{SiO}_{2}$ & 4.19 & 2.72 & 0.69 & 1.40 & 2.29 & 0.33 & 1.59 & 2.21 & 0.37 \\
\hline (2) $\mathrm{SiC}$ & 1.13 & 1.65 & $\sigma_{(1)}$ & 8.05 & 2.84 & $\sigma_{(1)}$ & 16.94 & 2.91 & $\sigma_{(1)}$ \\
\hline (3) $\mathrm{SiC}$ & - & - & - & 1.21 & 2.13 & $\sigma_{(1)}$ & 1.01 & 1.99 & $\sigma_{(1)}$ \\
\hline (4) $a-\mathrm{SiO}_{2}$ & $1.00^{*}$ & - & $0.55^{*}$ & $1.00^{*}$ & - & $0.29^{*}$ & $1.00^{*}$ & - & $0.50^{*}$ \\
\hline (5) $\mathrm{Si}$ (sub.) & - & - & $\sigma_{(4)}$ & - & - & $\sigma_{(4)}$ & - & - & $\sigma_{(4)}$ \\
\hline 2 weeks & $\mathrm{z}(\mathrm{nm})$ & $\rho\left(\mathrm{g} / \mathrm{cm}^{3}\right)$ & $\sigma(\mathrm{nm})$ & $\mathrm{z}(\mathrm{nm})$ & $\rho\left(\mathrm{g} / \mathrm{cm}^{3}\right)$ & $\sigma(\mathrm{nm})$ & $\mathrm{z}(\mathrm{nm})$ & $\rho\left(\mathrm{g} / \mathrm{cm}^{3}\right)$ & $\sigma(\mathrm{nm})$ \\
\hline (1) $\mathrm{SiO}_{2}$ & 4.38 & 2.74 & 0.73 & 1.57 & 2.26 & 0.37 & 1.68 & 2.22 & 0.41 \\
\hline (2) $\mathrm{SiC}$ & 0.99 & 1.56 & $\sigma_{(1)}$ & 7.91 & 2.79 & $\sigma_{(1)}$ & 16.88 & 2.89 & $\sigma_{(1)}$ \\
\hline (3) $\mathrm{SiC}$ & - & - & - & 1.40 & 2.16 & $\sigma_{(1)}$ & 1.20 & 2.04 & $\sigma_{(1)}$ \\
\hline (4) $a-\mathrm{SiO}_{2}$ & $1.00^{*}$ & - & $0.55^{*}$ & $1.00^{*}$ & - & $0.29^{*}$ & $1.00^{*}$ & - & $0.50^{*}$ \\
\hline (5) Si (sub.) & - & - & $\sigma_{(4)}$ & - & - & $\sigma_{(4)}$ & - & - & $\sigma_{(4)}$ \\
\hline 1 month & $\mathrm{z}(\mathrm{nm})$ & $\rho\left(\mathrm{g} / \mathrm{cm}^{3}\right)$ & $\sigma(\mathrm{nm})$ & $\mathrm{z}(\mathrm{nm})$ & $\rho\left(\mathrm{g} / \mathrm{cm}^{3}\right)$ & $\sigma(\mathrm{nm})$ & $\mathrm{z}(\mathrm{nm})$ & $\rho\left(\mathrm{g} / \mathrm{cm}^{3}\right)$ & $\sigma(\mathrm{nm})$ \\
\hline (1) $\mathrm{SiO}_{2}$ & 4.43 & 2.75 & 0.79 & 1.58 & 2.29 & 0.42 & 1.76 & 2.22 & 0.44 \\
\hline (2) $\mathrm{SiC}$ & 1.10 & 1.57 & $\sigma_{(1)}$ & 7.98 & 2.83 & $\sigma_{(1)}$ & 16.84 & 2.88 & $\sigma_{(1)}$ \\
\hline (3) $\mathrm{SiC}$ & - & - & - & 1.39 & 2.17 & $\sigma_{(1)}$ & 1.36 & 2.08 & $\sigma_{(1)}$ \\
\hline (4) $a-\mathrm{SiO}_{2}$ & $1.00^{*}$ & - & $0.55^{*}$ & $1.00^{*}$ & - & $0.29^{*}$ & $1.00^{*}$ & - & $0.50^{*}$ \\
\hline (5) $\mathrm{Si}$ (sub.) & - & - & $\sigma_{(4)}$ & - & - & $\sigma_{(4)}$ & - & - & $\sigma_{(4)}$ \\
\hline
\end{tabular}



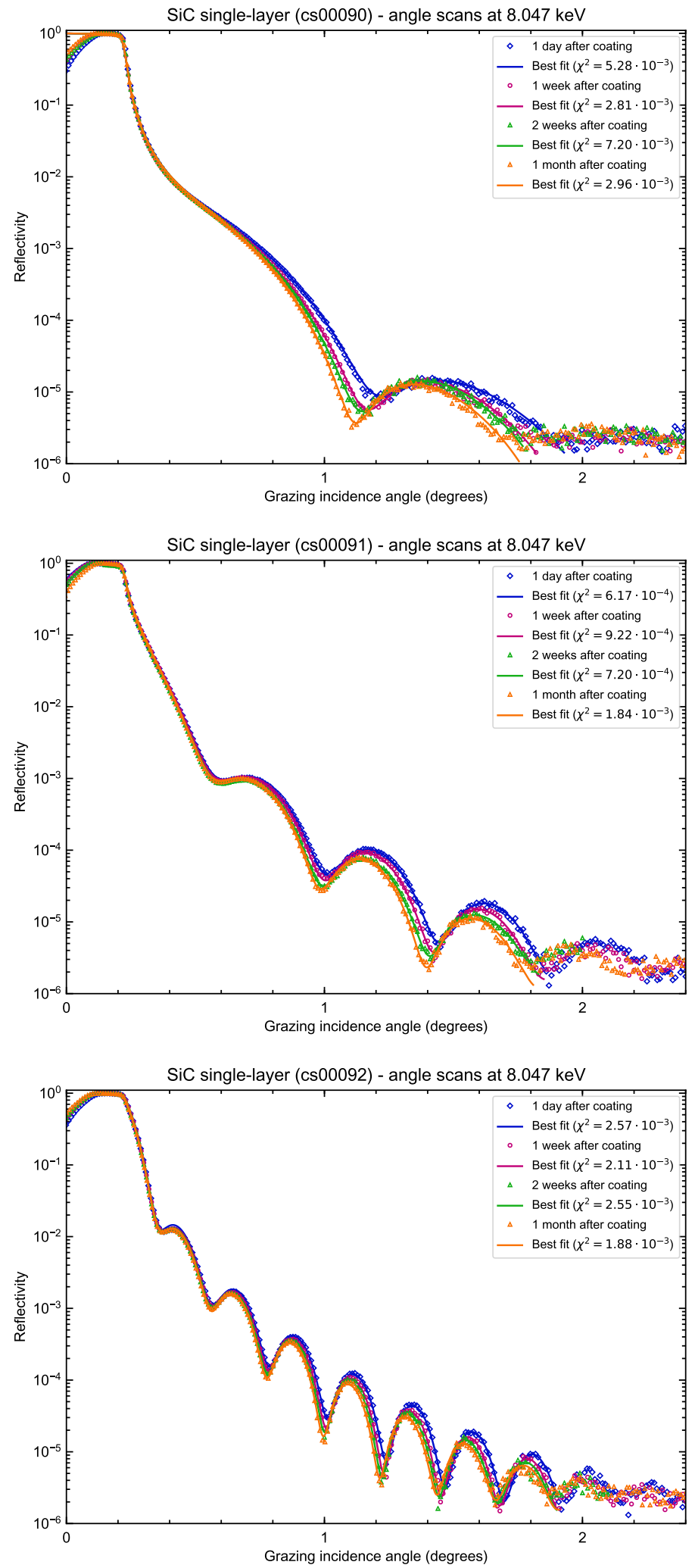

Figure 5: SiC single-layer coatings measured with XRR at $8.047 \mathrm{keV}$.

Proc. of SPIE Vol. 11119 111190G-8 
A simple single-layer $\mathrm{SiC}$ model is not sufficient to describe the XRR data, and as suggested by the XPS depth profiling, the single-layer film comprises several distinct layers. A possible explanation for this is that the initial sputter deposition causes atoms to form islands on the substrate, building an effective low-density $\mathrm{SiC}$ layer. Another contribution to the low-density transition layer could be hydrocarbon contamination of the substrate since the samples were not plasma cleaned prior to coating. As the sputtering proceeds, the $\mathrm{SiC}$ islands eventually coalesce, allowing for a denser packing which forms the continuous SiC film. Lastly, the top layer, which is exposed to the atmosphere as soon as the samples are removed from vacuum, is expected to exhibit yet a different morphology and lower density due to both incorporation of oxygen and hydrocarbon contamination. The XRR measurements were therefore modelled using a layer structure on top of a Si substrate with a $1 \mathrm{~nm}$ native a- $\mathrm{SiO}_{2}$ layer. The substrate roughnesses were assumed to be constant over time and were thus fixed to the fit value from the first measurements. For the thinnest $\mathrm{SiC}$ single-layer (cs00090; $\mathrm{z} \sim 5 \mathrm{~nm}$ ), fitting the data to a 3-layer model $\left(\mathrm{Si} / \mathrm{a}-\mathrm{SiO}_{2} / \mathrm{a}-\mathrm{SiC} / \mathrm{a}-\mathrm{SiO}_{2}\right)$ was sufficient to describe the data well and constrain all parameters. The remaining coatings had be be fitted with a 4-layer model $\left(\mathrm{Si} / \mathrm{a}-\mathrm{SiO}_{2} / \mathrm{a}-\mathrm{SiC} / \mathrm{a}-\mathrm{SiC} / \mathrm{a}-\mathrm{SiO}_{2}\right)$. The best fit parameters for all four samples are listed in Table 4. These results are in agreement with the observation that the films grow thicker over time and that the surface roughness increases, both of which are attributed to the $\mathrm{SiC}$ surface oxidation. Measurements with the new LEXR system will however allow for a more detailed mapping of the change in surface morphology.

\section{SUMMARY}

The long-term stability of $\mathrm{Ir} / \mathrm{SiC}$ coatings produced at DTU Space and cosine BV were studied by comparing XRR measurements taken 3 months after coating and onwards. We observe no significant degradation in performance for $\mathrm{Ir} / \mathrm{SiC}$ bilayers and periodic multilayers. The short-term stability of SiC single-layer coatings was studied in depth in terms of stucture, chemical composition and temporal stability using XPS and $8.047 \mathrm{keV}$ XRR. During the first month after coating, the $\mathrm{SiC}$ thin films evolve due to gradual oxidation of the surface. The XPS measurements reveal a composite structure of the films: A low-density transition layer on the native oxide of the substrate, followed by a continous film, and a top layer which is exposed to the atmosphere. XRR data of thicker $\mathrm{SiC}$ coatings $(\geq 10 \mathrm{~nm})$ are well-described by such a model. For the thinnest $\mathrm{SiC}$ coating $(\sim 5$ $\mathrm{nm}$ ), the structure parameters are constrained with a 3-layer model only, indicating that either the main film and top layer are averaged (limitation of the measurement) or that the oxidation is much more dominant through the film (distinct coating structure). Given the reported short-term evolution of $\mathrm{SiC}$, further studies need to assess whether a change in the surface chemical composition will have an impact on the compatibility with the industrialized SPO stacking procedures which could lead to a loss in overall telescope performance.

\section{ACKNOWLEDGEMENTS}

This activity has been funded by the European Space Agency under contract 4000102248/1/NL/PM, CCN3.

\section{REFERENCES}

[1] Nandra, K., Barret, D., Barcons, X., et al., "The Hot and Energetic Universe: A White Paper presenting the science theme motivating the Athena+ mission," astro-ph.HE arXiv:1306.2307 (2013).

[2] Jakobsen, A. C., Ferreira, D. D. M., Christensen, F. E., Shortt, B., Collon, M., and Ackermann, M. D., "Preliminary coating design and coating developments for ATHENA," Proceedings of SPIE 8147 (2011).

[3] Ferreira, D. D. M., Christensen, F. E., Jakobsen, A. C., Westergaard, N. J. S., and Shortt, B., "ATHENA coating optimization," Proceedings of SPIE 8443 (2012).

[4] Ferreira, D. D. M., Jakobsen, A. C., Christensen, F. E., et al., "Development and characterization of coatings on Silicon Pore Optics substrates for the ATHENA mission," Proceedings of SPIE 8443 (2012).

[5] Ferreira, D. D. M., Christensen, F. E., Jakobsen, A. C., et al., "Coating optimization for the ATHENA+ mission," Proceedings of SPIE $\mathbf{8 8 6 1}$ (2013).

[6] Ferreira, D. D. M., Jakobsen, A. C., Massahi, S., et al., "X-ray mirror development and testing for the ATHENA mission," Proceedings of SPIE 9005 (2016). 
[7] Massahi, S., Girou, D., Ferreira, D. D. M., et al., "Investigation of photolithography process on SPOs for the ATHENA mission," Proceedings of SPIE 9603 (2015).

[8] Ferreira, D. D. M., Massahi, S., Christensen, F. E., et al., "Design, development, and performance of X-ray mirror coatings for the ATHENA mission," Proceedings of SPIE 10399 (2017).

[9] Ferreira, D. D. M., Svendsen, S., Massahi, S., et al., "Performance and stability of mirror coatings for the ATHENA mission," Proceedings of SPIE 10699 (2018).

[10] Massahi, S., Christensen, F. E., Ferreira, D. D. M., et al., "The effect of nitrogen incorporation in boron carbide and iridium thin films," Proceedings of SPIE 10699 (2018).

[11] Lumb, D. H., Christensen, F. E., Jensen, C. P., and Krumrey, M., "Influence of a carbon over-coat on the X-ray reflectance of XEUS mirrors," Optics Communications 279 (2007).

[12] Oosterbroek, T., "ATHENA - Telescope reference design and effective area estimates," tech. rep., ESA (2018).

[13] Massahi, S., Christensen, F. E., Ferreira, D. D. M., Jafari, A., Svendsen, S., Henriksen, P. L., Shortt, B., Ferreira, I., Bavdaz, M., Collon, M., Landgraf, B., Girou, D., Langer, A., Schönberger, W., Wellner, T., Krumrey, M., and Cibik, L., "Installation and commissioning of the Silicon Pore Optics coating facility for the ATHENA mission," Proceedings of SPIE 11119 (2019).

[14] Roy, J., Chandra, S., Das, S., and Maitra, S., "Oxidation behaviour of silicon carbide - a review," Rev. Adv. Mater. Sci. 38 (2014).

[15] Windt, D., "IMD - Software for modeling the optical properties of multilayer films," Computers in Physics 12(4), 360-370 (1998).

[16] Vickery, A., Jensen, C. P., Christensen, F. E., et al., "Collimated Magnetron Sputter Deposition for Mirror Coatings," X-ray optics and instrumentation 2008 (2008).

[17] Krumrey, M. and Ulm, G., "High accuracy detector calibration at the PTB four-crystal monochromator beamline," Nucl. Instr. and Meth. A 1175 - 1178, 467 - 468 (2001).

[18] Björck, M., "Fitting with differential evolution: An introduction and evaluation," J. Appl. Cryst. 44 (2011).

[19] Henriksen, P. L., Christensen, F. E., Massahi, S., Ferreira, D. D. M., Svendsen, S., Jafari, A., and Shortt, B., "LEXR: A low-energy X-ray reflectometer for characterization of ATHENA mirror coatings," Proceedings of SPIE 11119 (2019).

[20] "CasaXPS: Processing Software for XPS, AES, SIMS and More." http://www. casaxps.com/.

[21] Moulder, J. F., Stickle, W. F., Sobol, P. E., and Bomben, K. D., [Handbook of X-ray Photoelectron Spectroscopy], Perkin-Elmer Corporation (1992).

[22] Wang, Y.-Y., Kusumoto, K., and Li, C.-J., "XPS Analysis of SiC Films Prepared by Radio Frequency Plasma Sputtering," Physics Procedia 32, 95-102 (2012).

[23] Kusunoki, I. and Igari, Y., "XPS study of a $\mathrm{SiC}$ film produced on $\mathrm{Si}(100)$ by reaction with a $\mathrm{C}_{2} \mathrm{H}_{2}$ beam," Applied Surface Science 59 (1992).

[24] Binner, J. and Zhang, Y., "Characterization of silicon carbide and silicon powders by XPS and zeta potential measurement," Journal of Materials Science Letters 20 (2001).

[25] Khung, Y. L., Ngalim, S. H., Scaccabarozzi, A., and Narducci, D., "Formation of stable Si-O-C submonolayers on hydrogen-terminated silicon(111) under low-temperature conditions," Beilstein journal of nanotechnology 6 (2015).

[26] "X-ray Photoelectron Spectroscopy (XPS) Reference Pages." https://www.xpsfitting.com. (2019-07-15).

[27] "ThermoScientific - XPS elements table." https://xpssimplified.com/elements. (2019-07-19).

[28] Jacobsohn, L. G., Schulze, R. K., Maia da Costa, M. E. H., and Nastasi, M., "X-ray photoelectron spectroscopy investigation of boron carbide films deposited by sputtering," Surface Science 10399 (2004). 